\title{
A SYSTEM OF GENERALIZED AUXILIARY PROBLEMS PRINCIPLE AND A SYSTEM OF VARIATIONAL INEQUALITIES
}

\author{
RAM U. VERMA
}

Abstract. The approximation-solvability of a system of nonlinear variational and quasivariational inequalities $(S N V Q V I)$

$$
\left\langle F_{1}\left(x^{*}, y^{*}\right), x-x^{*}\right\rangle \geqslant 0 \text { for all } x \in X
$$

and

$$
\left\langle F_{2}\left(x^{*}, y^{*}\right), g(y)-g\left(y^{*}\right)\right\rangle \geqslant 0 \text { for all } g(y) \in Y,
$$

where $X$ and $Y$, respectively, are nonempty closed convex subsets of $\mathbf{R}^{m}$ and $\mathbf{R}^{n}$ and related $F_{1}: X \times Y \rightarrow \mathbf{R}^{m}$ and $F_{2}: X \times Y \rightarrow \mathbf{R}^{n}$ are any mappings such that $F=\left(F_{1}, F_{2}\right)$ is $g-\gamma$-partially relaxed monotone, is presented. Here $g: \mathbf{R}^{n} \rightarrow \mathbf{R}^{n}$ is any mapping.

Mathematics subject classification (2000): 49J40.

Key words and phrases: System of variational inequalities, cocoercive mapping, partially relaxed monotone mapping, approximation-solvability, approximate solutions.

\section{REFERENCES}

[1] C. BAIOCCHI AND A. CAPELO, Variational and Quasivariational Inequalities, Wiley \& Sons, New York, 1984.

[2] G. CoHEN, Auxiliary problem principle extended to variational inequalities, J. Optim. Theo. Appl. 59 (2) (1988), 325-333.t.

[3] J. C. DunN, Convexity, monotonicity and gradient processes in Hilbert spaces, J. Math. Anal. Appl. 53 (1976), 145-158.

[4] J. S. GUO AND J. C. YAO, Extension of strongly nonlinear quasivariational inequalities, Appl. Math. Letters 5 (3) (1992), 35-38.

[5] B. S. HE, A new method for a class of linear variational inequalities, Math. Programming 66 (1994), 137-144.

[6] B. S. HE, A class of projection and contraction methods for monotone variational inequalities, Applied Math. Optim. 35 (1997), 69-76.

[7] D. Kinderlehrer and G. Stampacchia, An Introduction to Variational Inequalities, Academic Press, New York, 1980.

[8] G. M. KoRPELEVICH, The extragradient method for finding saddle points and other problems, Matecon 12 (1976), 747-756.

[9] P. Marcotte And J. H. Wu, On the convergence of projection methods, J. Optim. Theory Appl. 85 (1995), 347-362.

[10] J. S. PANG AND D. CHAN, Iterative methods for variational and complementarity problems, Math. Programming 24 (1982), 284-313.

[11] R. U. VERMA, Nonlinear variational and constrained hemivariational inequalities involving relaxed operators, ZAMM 77 (5) (1997), 387-391.

[12] R. U. VERMA, RKKM mapping theorems and variational inequalities, Math. Proc. Royal Irish Acad. 98A (2) (1998), 131-138. 
[13] R. U. Verma, Generalized pseudocontractions and nonlinear variational inequalities, Publ. Debrecen 33 (1-2) (1998), 23-28.

[14] R. U. VERMA, An iterative algorithm for a class of nonlinear variational inequalities involving generalized pseudocontractions, Math. Sci. Res. Hot-Line 2 (5) (1998), 17-21.

[15] R. U. VERMA, Strongly nonlinear quasivariational inequalities, Math. Sci. Res. Hot-Line 3 (2) (1999), $11-18$.

[16] R. U. VERMA, Approximation-solvability of nonlinear variational inequalities involving partially relaxed monotone (prm) mappings, Adv. Nonlinear Var. Inequal. 2 (2) (1999), 137-148.

[17] R. U. VERMA, An extension of a class of nonlinear quasivariational inequality problems based on a projection method, Math. Sci. Res. Hot-Line 3 (5) (1999), 1-10.

[18] R. U. Verma, Approximation-solvability of a system of nonlinear quasivariational inequalities involving partially relaxed monotone mappings, Math. Sci. Res. Hot-Line 4 (4) (2000), 47-61.

[19] R. U. VERMA, On a class of nonlinear implicit variational inequalities involving partially relaxed monotone and partially strongly monotone mappings, Math. Inequal. Appl. (to appear).

[20] R. U. VERMA, A new class of iterative algorithms for approximation-solvability of nonlinear variational inequalities, Computers Math. Appl. (to appear).

[21] E. ZEIDLER, Nonlinear Functional Analysis and its Applications I, Springer-Verlag, New York, 1986.

[22] D. L. ZHU AND P. MARCOTTE, Co-coercivity and its role in the convergence of iterative schemes for solving variational inequalities, SIAM J. Optim. 6 (3) (1996), 714-726. 